\title{
Investigating burn cases, knowledge, attitudes and practices to burn care and prevention in Ethiopia: a community-survey
}

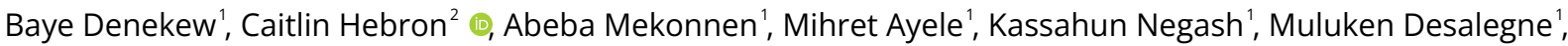 \\ Patricia Price ${ }^{2}$, Tom Potokar ${ }^{2}$ \\ ${ }^{1}$ Amref Health Africa in Ethiopia, Addis Ababa, Ethiopia, ${ }^{2}$ Centre for Global Burn Injury Policy and Research, Swansea University, Swansea, United \\ Kingdom \\ Keywords: community survey, participatory approach, epidemiology, implementation science, burn injuries \\ https://doi.org/10.29392/001c.24353
}

\section{Journal of Global Health Reports}

Vol. 5, 2021

\begin{abstract}
Background
Burn injuries are thought to be preventable but are still a prevalent global health problem, especially in low- and middle- income countries, including Ethiopia. According to the 2016 Ethiopian Demographic and Health Survey report, burn injuries represent 8.7\% of all significant injuries in Ethiopia. Such injuries result in catastrophic consequences for patients; to reduce this burden of injury, we need to ensure that future community-based burn prevention and treatment interventions are effective, available and evidence based. The main objective of this study was to assess the magnitude and causes of burn injuries as well as the knowledge, attitude and practice towards burns of community members to create an evidence base for improving basic burn care services focusing on prevention.
\end{abstract}

\section{Methods}

This cross sectional study was conducted in three districts (Dembiya, Limu Genet and Tula) found in Amhara, Oromia and Southern Nations, Nationalities, and People's Region (SNNPR) regional states. 651 households were selected using multi-stage cluster sampling method.

\section{Results}

The survey team asked households if anyone in the selected household had experienced a burn injury within the past 12 months; 3.5\% of these households reported a burn injury (using WHO definition), which was equivalent to $0.7 \%$ of all individuals from the surveyed households. Of the individuals who experienced a burn, the majority were female (14 of $23,60.9 \%$ ) and children under five (14 of $23,60.9 \%$ ); households with a separate 'house' for cooking had an $85.9 \%$ reduction in their chances of experiencing a burn injury. The main causes of burn injuries were heat, flame and hot liquid water (89.7\%) and all 23 burn injuries occurred at home. A significant number of community members still used traditional practices to treat a burn injury, like applying dough and oil.

\section{Conclusions}

This research highlights the importance of improving community awareness and knowledge on burn prevention methods, with recognition that women and children are high risk groups. The research also demonstrates the need to develop the capacity of health facilities at all levels, through appropriate training and resources, to enable them to provide quality health care service to the community.

The distribution of disease, death and injury globally can be seen as a reflection of the differing economic, social and political climates that exist in the world, with low- and middle-income countries (LMICs) sustaining disproportionately worse health outcomes than their high-income counterparts. ${ }^{1}$ Burn injuries are no exception, with $95 \%$ of flame-related burns occurring in low and middle-income countries. ${ }^{2}$ This disparity is exacerbated by the capacity of high-income countries to implement proven prevention strategies and provide high quality care for burn patients, whereas a lack of resources prevents low-income countries from taking the same approach. With burns being a leading cause for disability-adjusted life years in LMICs and there being more than 180,000 deaths attributed to burns annually, ${ }^{3,4}$ it is appropriate to consider burns to be a global public health crisis. 
In high-income countries, there have been dramatic advances in clinical burn care paired with successful implementation of prevention strategies and increased public awareness. ${ }^{5}$ The result of these improvements is a significant decrease in burn injuries and an increase in appropriate, high-quality treatment. In contrast to this, many LMICs still lack effective prevention strategies leading to an unreasonably high incidence of burn injuries, often without access to even basic care, leading to avoidable death, disability and stigma. With this in mind, burn-mitigating strategies should focus on how to take proven interventions and implement them in LMICs.

Ethiopia is classed as a low-income country, according to the Organisation for Economic Co-operation and Development. ${ }^{6}$ Their 2016 demographic and health survey indicated a high burn injury rate, with $8.7 \%$ of household members being injured or killed by a burn injury in the 12 months prior to the survey. ${ }^{7}$ Although this information is useful in understanding the burden of burns in Ethiopia, it does little to elucidate the underlying specifics of the cause of the injury or the knowledge, attitudes and practices (KAP) of the communities in which the burns occurred. It is crucial to understand the causes underlying burns and KAPs surrounding burns injuries in different communities. This information is necessary to successfully create and implement burn prevention strategies in order to make them context specific.

This study was designed to address the lack of in-depth, local information on burn incidence and aimed to investigate both the incidence and causes of burn injuries in three districts in Ethiopia - Dembiya, Limu Genet and Tula - as well as the KAPs of the same communities through the employment of a standardised community survey. The results from the survey will be used to inform a locally led, contextually relevant community prevention and first aid strategy.

\section{METHODS}

This study was a community survey conducted across three districts in Ethiopia: Dembiya district in Amhara region, Limu Genet District in Oromia Region, and Tula District in Southern Region. These locations were purposively selected on the basis that the Ministry of Health plans to establish burn units in the three hospitals proximal to the respective areas. The survey collected information on the incidence, risk factors and KAPs surround burn injuries.

A multi-stage stratified sample using probability proportional to size approach (as per WHO guidelines for sample size calculation method ${ }^{8}$ ) was used to select kebeles; kebeles are the smallest administrative unit of Ethiopia. Systematic random sampling was deployed to select the households in each kebele. In each district, a minimum of 12 kebeles were covered, and in each kebele a minimum of 12 households were selected using a systematic sampling procedure. Using the WHO guidelines, ${ }^{8}$ a minimum of 209 households were required; however, the data collectors were able to cover more than the expected household size (i.e., a total of 216 in Dembiya, 216 in Tula and 219 in Limu Genet) so the total sample households covered was 651 . The data collectors started in the center of the Kebele and selected every tenth household. The survey was conducted over 15 days, beginning on February $20^{\text {th }}, 2019$.

Data was collected using Open Data Kit (ODK) software downloaded onto a mobile tablet. 12 data collectors were selected in consultation with the regional government health bureaus and district health offices; all data collectors were health professionals, fluent in the local language with previous data collection experience. The data collectors attended a two day training course, which included practicing how to use the tablet correctly and how to collect data using ODK to ensure systematic, consistent data entry.

After training and prior to the full data collection, there was a one-day pilot data collection period to ensure that the data collectors understood the methods and procedures. Any queries from this period were addressed and minor amendments were made to optomise the survey for the data collectors and make it user-friendly for the participants. During the main data collection period, each team of three data collectors had a supervisor for quality assurance purposes and to assist with any problems. Additionally, the data collected in ODK was checked daily to certify that it was being inputted correctly.

The data was transferred to SPSS version 20 and descriptive analysis was conducted and presented using frequency tables. Detailed analysis included using Chi -square test and Binary Logistic Regression when there were statistically significant variations among socio- demographic factors and to examine how these factors (dependent variables) determined the occurrence of burn injuries (outcome variable). Prior to the survey, ethical clearance was obtained from the Ethiopian Public Health Institute Ethical Review Committee of the Federal Democratic Republic of Ethiopia. This research was funded by the National Institute for Health Research (NIHR) (16.137.110) using UK aid from the UK Government to support global health research. The views expressed in this publication are those of the author(s) and not necessarily those of the NIHR or the UK government.

The qualitative data collected in this study included key informant interviews (KIIs) in each district, comprising one health center head/representative, one Kebele chairman and one Health Extension Worker (HEWs). In addition, one focus group discussion (FGD) per district was conducted including elder people, women, and religious leaders. The data was collected from established members of the community to enrich the quantitative findings through acquisition of local knowledge on the various burn risk factors. The qualitative data was transcribed, reviewed, summarized and triangulated with the findings of the quantitative data.

\section{RESULTS}

\section{DEMOGRAPHICS}

The survey was completed by a 651 households across the 3 areas, with each household having at least one valid reponse. There was an average of 5 members per household, thus information on 3276 family members was collected (Table 1). All burn injuries reported were considered, regardless of severity.

Of the information from the 3267 family members, 1160 (35.4\%) were from Limu Genet district, 1074 (32.8\%) were from Dembiya district and 1042 (31.8\%) were from Tula dis- 
Table 1. Demographic information of all the study participants across all surveyed households.

\begin{tabular}{|l|l|}
\hline Demographic characteristics & Total household members ( $\mathrm{N}=\mathbf{3 2 7 6}$, total households $=651$ ) \\
\hline Gender & $1679(51.3 \%)$ \\
\hline Male & $1597(48.7 \%)$ \\
\hline Female & $1074(32.8 \%)$ \\
\hline District & $1160(35.4 \%)$ \\
\hline Dembiya (Frequency, \% of $\mathrm{N})$ & $1042(31.8 \%)$ \\
\hline Limu Genet (Frequency, \% of $\mathrm{N})$ &
\end{tabular}

Table 2. Demographic information of all the individuals from the surveyed households who reported to have sustained a burn

\begin{tabular}{|l|l|}
\hline Individuals who sustained a burn in the 12 months prior to the survey & Number (N=23) \\
\hline Gender & $9(39 \%)$ \\
\hline Male (frequency, \%) & $14(61 \%)$ \\
\hline Female (frequency, \%) & $17(2.6 \%)$, \\
\hline District & $2(0.3 \%)$ \\
\hline Dembiya & $4(0.6 \%)$ \\
\hline Limu Genet & \multicolumn{2}{|l}{} \\
\hline Tula & $4(17.4 \%)$ \\
\hline Age group & $10(43.5 \%)$ \\
\hline Infant (under age one) (frequency, \% of N) & $6(26.1 \%)$ \\
\hline Children between age one and five (frequency, \% of N) & - \\
\hline Age between 5 and 15 (frequency, \% of N) & $3(13 \%)$ \\
\hline Age between 15 and 24 (frequency, \% of N) & - \\
\hline Age between 25 and 49 (frequency, \% of N) & \\
\hline Over 49 & \\
\hline
\end{tabular}

trict. Among the family members $51.3 \%$ were male and the remaining were females. Table 1 outlines the demographic characteristics.

The housing type (e.g., mud, concrete) and the place of cooking (e.g., separate kitchen, no separate kitchen) was recorded and the results are shown in Table 3 .

\section{MAGNITUDE OF BURN INJURIES AND BURN CHARACTERISTICS}

The WHO defines a burn as "an injury to the skin or other organic tissue primarily caused by heat but can also be due to radiation, radioactivity, electricity, friction or contact with chemicals." ${ }^{3}$ Using this definition, the results of the survey indicated there was a total of 23 burn injuries within the previous 12 months observed across all households involved in the survey. This represents $0.7 \%$ of all survey participants from $3.5 \%$ of the total surveyed households.

As shown in Table 2, the majority of burn injuries (74\%) occurred in the Amhara Region in the Dembiya district. Among the 23 burn injuries, the majority 14 (60.9\%) were female. Children under age 15 experienced $87 \%$ of all the burn injuries and among these, 14 (60.9\%) were under five years old.

\section{CAUSES AND TREATMENT OF BURN INJURIES}

All of the recorded burn injuries from the survey occurred in the household. A total of 18 were accidental, and 5 were intentional. The major causes were heat and flame $(\mathrm{N}=12$, $52.2 \%$ ), followed by hot liquid ( $\mathrm{N}=10,43.5 \%$ ) and one person (4.3\%) sustained an electrical burn.

Considering burn injury occurrence in the past 12 months before the survey as an outcome variable and type of house and place where cooking take place as dependent variables, binary logistic regression analysis indicated that cooking in a 'separate house' made a statistically significant contribution for not having burn injury occurrence compared with cooking inside the house with no separate kitchen (see Table 4), such that having a 'separate house' for cooking led to a $85.9 \%$ reduction in your chance of experiencing a burn injury while cooking.

Home treatments were undertaken for 20 (87\%) of the burn injuries occurring in the past 12 months. The most 
Table 3. Type of house and method of cooking in each surveyed household, by study district.

\begin{tabular}{|c|c|c|c|c|}
\hline House characteristics & $\begin{array}{l}\text { Dembiya } \\
(\mathrm{N}=216)\end{array}$ & $\begin{array}{l}\text { Limu Genet } \\
(\mathrm{N}=219)\end{array}$ & $\begin{array}{l}\text { Tula } \\
(\mathrm{N}=216)\end{array}$ & $\begin{array}{l}\text { Total }(\mathrm{N}= \\
651)\end{array}$ \\
\hline \multicolumn{5}{|l|}{ Type of household } \\
\hline Concrete (frequency, \%) & 0 & 1 & $11(5 \%)$ & $12(2 \%)$ \\
\hline Thatched house (frequency, \%) & $0(0 \%)$ & $9(4 \%)$ & $46(21 \%)$ & $55(8 \%)$ \\
\hline Mud wall and corrugated Iron sheet (frequency, \%) & $75(35 \%)$ & 45 (21\%) & $5,2 \%$ & $125(19 \%)$ \\
\hline $\begin{array}{l}\text { Wood wall and corrugated Iron sheet (frequency, } \\
\% \text { ) }\end{array}$ & $141(65 \%)$ & $164(75 \%)$ & $154(71 \%)$ & $459(71 \%)$ \\
\hline Total & 216 & 219 & 216 & 651 \\
\hline \multicolumn{5}{|l|}{ Place where cooking take place } \\
\hline $\begin{array}{l}\text { Inside the house, No separate Kitchen (frequency, } \\
\% \text { of N) }\end{array}$ & $39(18 \%)$ & $23(11 \%)$ & $25(12 \%)$ & $87(13 \%)$ \\
\hline $\begin{array}{l}\text { Inside the house, with separate kitchen (frequency, } \\
\% \text { of N) }\end{array}$ & $11(5 \%)$ & $10(5 \%)$ & $13(6 \%)$ & $34(5 \%)$ \\
\hline In a separate house (frequency, \% of $\mathrm{N}$ ) & $24(11 \%)$ & $163(74 \%)$ & $145(67 \%)$ & $332(51 \%)$ \\
\hline Both (frequency, \% of $\mathrm{N}$ ) & $129(60 \%)$ & $19(7 \%)$ & $25(12 \%)$ & $173(27 \%)$ \\
\hline Outdoors (frequency, \% of $\mathrm{N}$ ) & $13(6 \%)$ & $4(2 \%)$ & $8(3.7 \%)$ & $25(4 \%)$ \\
\hline Total & 216 & 219 & 216 & 651 \\
\hline \multicolumn{5}{|l|}{ Type of Cooking stove used in the house* } \\
\hline Three stones (frequency, \%) & $214(99 \%)$ & $218(100 \%)$ & $189(88 \%)$ & 621 \\
\hline Coal pot (frequency, \%) & $66(31 \%)$ & $28(13 \%)$ & $52(24 \%)$ & $146(22 \%)$ \\
\hline Kerosene (frequency, \%) & $2(1 \%)$ & $0(0 \%)$ & $0(0 \%)$ & $2(0 \%)$ \\
\hline Electricity (frequency, \%) & $5(2 \%)$ & $13(6 \%)$ & $22(10 \%)$ & $40(6 \%)$ \\
\hline Total & 287 & 259 & 263 & 809 \\
\hline
\end{tabular}

Table 4. Binary Logistic Regression Analysis on the effect of type of house and cooking place on burn injury outcome

\begin{tabular}{|c|c|c|c|c|c|c|c|c|}
\hline \multirow{2}{*}{ Data } & \multicolumn{6}{|c|}{ Statistics } & \multicolumn{2}{|c|}{$\begin{array}{l}95 \% \text { confidence interval } \\
\text { for } \operatorname{EXP}(B)\end{array}$} \\
\hline & B & SE & Wald & df & Sig & $\operatorname{Exp}(B)$ & Lower & Upper \\
\hline \multicolumn{9}{|l|}{ Type of House } \\
\hline Intercept & & & 2.921 & 3 & 0.404 & & & \\
\hline Thatched house & -2.602 & 1.54 & 2.855 & 1 & 0.091 & 0.074 & 0.004 & 1.516 \\
\hline $\begin{array}{l}\text { Mud wall with corrugated } \\
\text { Iron }\end{array}$ & -1.234 & 1.246 & 0.98 & 1 & 0.322 & 0.291 & 0.025 & 3.35 \\
\hline $\begin{array}{l}\text { Wooden wall with } \\
\text { Corrugated Iron }\end{array}$ & -1.26 & 1.155 & 1.189 & 1 & 0.275 & 0.284 & 0.029 & 2.73 \\
\hline \multicolumn{9}{|c|}{ Place where cooking usually preformed (Inside the house, with no separate kitchen as a reference) } \\
\hline Intercept & & & 11.059 & 4 & 0.026 & & & \\
\hline $\begin{array}{l}\text { Inside the house, with } \\
\text { separate kitchen }\end{array}$ & -1.482 & 1.141 & 1.687 & 1 & 0.194 & 0.227 & 0.024 & 2.127 \\
\hline In separate house & -1.962 & 0.609 & 10.386 & 1 & 0.001 & 0.141 & 0.043 & 0.464 \\
\hline Both & -0.563 & 0.565 & 0.993 & 1 & 0.319 & 0.57 & 0.188 & 1.723 \\
\hline Outdoors & -1.026 & 1.107 & 0.858 & 1 & 0.354 & 0.359 & 0.041 & 3.142 \\
\hline Constant & -0.987 & 1.187 & 0.692 & 1 & 0.405 & 0.373 & & \\
\hline
\end{tabular}

common type of treatments used by the community was the use of dough made of "Teff powder" used on 10 of the burn injuries. The other types of home treatment were the application of a leaf "Esat Abrid”, oil, milk, coffee powder, lotion, 
Table 5. Descriptive table showing various burn treatments and reasoning reported from the surveyed households.*

\begin{tabular}{|c|c|}
\hline Why you did the home treatment?* & Number $(\mathrm{N}=\mathbf{2 0})$ \\
\hline I had applied it before & $5(25 \%)$ \\
\hline Family members suggested to do so & $7(35 \%)$ \\
\hline I had heard about it before & $12(60 \%)$ \\
\hline I just did & $1(5 \%)$ \\
\hline Neighbours suggested & $1(5 \%)$ \\
\hline After the injury, was the burn patient taken to any type of facility? & $\mathrm{N}=\mathbf{2 3}$ \\
\hline Yes & $13(56.5 \%)$ \\
\hline No & $10(43.5 \%)$ \\
\hline Reason for not taking to other places & $\mathrm{N}=10$ \\
\hline Had a belief in home treatment & $7(70 \%)$ \\
\hline Lack of money & $2(20 \%)$ \\
\hline No particular reason & $1(10 \%)$ \\
\hline If you went for treatment to other places, where did you go first? & $\mathrm{N}=13$ \\
\hline Health center & $11(84.6 \%)$ \\
\hline Primary hospital & $1(7.7 \%)$ \\
\hline Private clinic & $1(7.7 \%)$ \\
\hline Did household income decline because of Injury? & $\mathrm{N}=\mathbf{2 3}$ \\
\hline Yes, a big decline & $4(17.4 \%)$ \\
\hline Yes, a slight decline & $4(17.4 \%)$ \\
\hline No & $15(65.2 \%)$ \\
\hline Did the household supply (i.e., changes to household living conditions) decline because of the injury & $\mathrm{N}=\mathbf{2 3}$ \\
\hline Yes & $5(21.7 \%)$ \\
\hline No & $16(69.6 \%)$ \\
\hline Refused to say & $1(4.3 \%)$ \\
\hline Did the injured person stop education because of the injury? & $N=23$ \\
\hline Yes & $2(8.7 \%)$ \\
\hline No & $18(78.3 \%)$ \\
\hline Not applicable & $3(13 \%)$ \\
\hline Did they lose their job because of injury? & $N=23$ \\
\hline Yes & $4(17.4 \%)$ \\
\hline No & $17(74 \%)$ \\
\hline Not applicable & $2(8.7 \%)$ \\
\hline
\end{tabular}

*More than one response was possible

water and salt. They applied the home treatment mainly because they heard about it from others $(60 \%)$ or their family members suggested it (35\%) (Table 5).

Among the injured persons occurring in the past 12 months before the survey, 13 (56.5\%) were taken to health facilities (health center, primary hospital or a private clinic) for treatment and 10 (43.5\%) were treated at home.

Regarding the socio-economic impact of the injury on the household, 8 (34.8\%) said that their household income declined because of the injury; 15 (21.7\%) mentioned their household income was not affected, 2 (8.7\%) stopped school for a few days; and 4 (17.4\%) lost their jobs because of the injury (Table 5).

\section{KNOWLEDGE, ATTITUDE AND PRACTICE ABOUT BURN INJURIES}

Respondents were asked a range of questions to try get a better understanding of their knowledge, attitudes and practice towards burn injuries.

Of the respondents, $63.6 \%$ disagreed or strongly disagreed that burns can cause bad scars; $89.2 \%$ believed that most burns are preventable and $66.4 \%$ mentioned that most 
Table 6. Descriptive table illustrating the answers given by households on their perception of risk factors for burn injuries

\begin{tabular}{|c|c|}
\hline Questions & No. (\%) \\
\hline Possible cause of burn injuries for the next 12 months & $N=651$ \\
\hline Heat and Flame & $394(60.5 \%)$ \\
\hline Electric Current & $66(10.1 \%)$ \\
\hline Hot liquid & $160(24.6 \%)$ \\
\hline Chemicals & $9(1.4 \%)$ \\
\hline Do not know & $22(3.4 \%)$ \\
\hline Type of family members with a high possibility of getting burn injury in the next 12 months* & $N=651$ \\
\hline Children & $428(64.2 \%)$ \\
\hline Women & $202(31 \%)$ \\
\hline Men & $2(0.03 \%)$ \\
\hline Don't know & $7(1.1 \%)$ \\
\hline Missed & $27(4.1 \%)$ \\
\hline Possible time of getting burn injuries & $N=651$ \\
\hline Morning & $133(20.4 \%)$ \\
\hline Afternoon & $287(44.1 \%)$ \\
\hline Night & $162(24.9 \%)$ \\
\hline Do not know & $58(8.9 \%)$ \\
\hline At any time & $10(1.5 \%)$ \\
\hline Missing & $1(0.01 \%)$ \\
\hline Burn can cause bad scars & $N=651$ \\
\hline Agree & $231(35.5 \%)$ \\
\hline Neutral & $6(0.9 \%)$ \\
\hline Disagree & $4(0.6 \%)$ \\
\hline Strongly disagree & $410(63 \%)$ \\
\hline Most burns are preventable & $N=651$ \\
\hline Strongly agree & $221(33.9 \%)$ \\
\hline Agree & $360(55.3 \%)$ \\
\hline Neutral & $39(6 \%)$ \\
\hline Disagree & $30(4.6 \%)$ \\
\hline Strongly disagree & $1(0.2 \%)$ \\
\hline
\end{tabular}

*More than one response was possible

people with burns will die as a result of their injury (Table 6).

When respondents were asked what they would do if they split hot liquid on themselves, or on their family members, $69.6 \%$ said that they would apply oil; $50.8 \%$ said that they would put dough on it and only $25.3 \%$ said they would apply cold water. Other methods were also mentioned such as use of aloe vera, coffee powder, milk, alcohol or soil. The participants were also asked what they would do if their clothing caught fire, $84.3 \%$ stated that they would pour water on the flames, $51.2 \%$ said they would take off their clothing and 6.1\% expressed them would stop, drop and roll.

Participants were asked where they would take someone from their family who received a small/minor burn. The majority (75\%) said that they would take them to health center, but a significant amount (15.4\%) also stated that they would take them to a herbalist/ traditional practitioner. Other places mentioned by the respondents were health posts (9.2\%), pharmacy (6.1\%) and HEWs (3.5\%).

The participants were asked about what they thought might cause burn injuries for themselves and family members. Many of the respondents $(60.5 \%)$ said that it could be due to heat and flame, 157 (24.1\%) mentioned hot liquid (including steam or gas), while electric current was mentioned by 66 (10.1\%) respondents. Many of respondents (64.2\%) stated that they thought children were the most vulnerable family members for burns, followed by women (31\%).

Cooking/eating at home was mentioned by $33.9 \%$ of respondents as a perceived risk factor for burns and $12 \%$ 
stated working outside of the household was a perceived risk factor.

\section{QUALITATIVE RESULTS}

In discussion with the Kebele leaders, it was stated that the major causes of burn in the community were from hot water/coffee, burns from cooking and other household associated burns. The participants expressed the view that the local community did not have adequate knowledge about how to treat burn injuries.

Participants from the Dembiya district discussed how gender roles mean women keep a fire all day in the kitchen. This is in order to cook, and to bake traditional "engera" and prepare the drink "tela", both of which, according to societal norms, should always be available in each household. The participants stated that this continuous fire-keeping makes women vulnerable to flame injuries, as well as an increased risk of burns in the household due to flammable materials, such as grass, often making up parts of the kitchen infrastructure. As children are often kept close to their mothers in the kitchen, they too are at high risk for fire burns.

Further risks to children were discussed; participants said older children often look after their younger siblings, and when the older children go to school the younger children can be left unattended, increasing their exposure to burn hazards. The participants reported that the most affected group for burn injuries were children under three years old.

Among the leaders of the health centers, there was a detailed discussion on the lack of capacity to deal with burns. They detailed that health workers in the selected health centers were not trained in burn management, compounded by a lack of adequate facilities. This was backed up by the HEWs who explained that they did not know about appropriate burn care, and that most of the community would not come to them due to their lack of expertise. This view was reflected by one of the Kebele chairman: "even if our people are taking the injured family to health facilities, they didn't get enough treatment so that the community instead try to use cultural medicine".

Members of the FGDs reinforced the lack of healthcare capacity. They said that they did not get adequate treatment for burns at health facilities as the health workers would just apply Gentian Violet and send them home.

\section{DISCUSSION}

There is a dearth of literature surrounding community level knowledge on burns in Ethiopia. The information from this study is therefore novel and should be used to aid the development of future interventions and policy aimed at reducing the incidence and severity of burns in these districts in Ethiopia. Although the information provided is highly contextual, the model of collecting local data to inform health activities tailored to the study communities is transferable. This is especially relevant in low-income settings where there is often a paucity of relevant local information to inform policy and interventions.

The data indicates that participants may have inaccurate perceptions of burn injuries, given that $66 \%$ recorded that they believed that most people die from burn injuries. At the same time almost $90 \%$ believe that burn injuries are preventable, suggesting that they may be open to prevention and awareness raising interventions.

It is evident from this study that burns present a problem, with $0.7 \%$ of the study population reporting a burn within the previous 12 months. This result is in line with a recent review of burn prevalence in Ethiopia that found results spanning from 0.1 to $1.2 \%{ }^{9}$ Women and children were the most likely to experience a burn injury, a pattern which is reflected in much of the pre-existing epidemiological data surrounding burn injuries. ${ }^{10-12}$ All burns occurred in the household; with data strongly supporting the use of a separate location for cooking as a key driver in preventing burn injuries during cooking related activities. Due to the traditional roles of women in the studied areas of Ethiopia, the women are expected to be in the home most of the day preparing various food and drinks over a fire, exposing them to burn hazards. Children are often with mothers while they are cooking meaning they are also exposed to this risk. Another explanation for children being at high risk was given in the FGDs, suggesting that when older siblings begin education, younger children can be left with no one to look after them if the parents are elsewhere. This is clearly a complicated scenario relating to socioeconomics with no panacea solution. However, it does present clear implications for increasing burn awareness activities that specifically target and support women and children in the community. This notion is reinforced by the large percentage of the study participants who relied on home treatments for burns, often which were not best practice, such as applying oil to the injury.

The qualitative results from the study highlighted the lack of healthcare capacity, specifically within HEWs, to adequately manage burns, as well as insufficient knowledge in the community on how to manage and prevent burn injuries. The main recommendations therefore suggest capacity-development for HEWs to improve their burn management skills and knowledge; this is very important in the Ethiopian context where HEWs are at the forefront of communicating with the community on various health packages. This provides the opportunity to present burn awareness and prevention programs, tailored for the high-risk groups that should target context specific risk factors such as addressing existing harmful first aid practices like applying dough to burns, whilst encouraging discussion and providing information about the appropriate measures.

The research showed that there was a significant reliance on traditional medicine, with $15.4 \%$ of respondents suggesting in the case of a family member getting burned, they would take them to a herbalist/traditional healer. It is therefore important to incorporate traditional practitioners in future strategies to improve burn care, to integrate appropriate methods of burn management into their practice. This notion is supported by the WHO Traditional Medicine (TM) Strategy; the central aim of this strategy is "integrating TM products, practitioners and practice into health systems, where appropriate." 13 With there being such a high reliance on TM, not just in the context of this study, but all over the world for a spectrum of health ailments, it is im- 
portant to be proactive in strengthening their role in the health system and supporting TM practitioners to give the best possible care.

The survey also reflected the significant economic and education toll the injuries had on those affected. This is especially detrimental in a setting where many are already in economically challenging situations. In this respect, prevention of the burn occurring is, again, paramount.

The study has a range of limitations which means that caution should be used when interpreting the results. For example, participants had to recall events over the previous 12 months raising the issue of recall bias that in inherent in any retrospective survey design. A larger sample of participants from different parts of the country may have given a more detailed and representative set of results from a national perspective, although the procedures for recruitment were in line with WHO recommendations ${ }^{8}$ ensuring that the sample were representative of the local population. However, one of the strengths of the study is the emphasis on community participation in understanding the local context. There is a small possibility that the members of the team of researchers interpreted the questions in the survey differently when interacting with households; however, we are confident that the detailed training that they received before the start of the study and the use of the Open Data Software ensured a consistent approach was used. Further work will be needed to understand the background to the 5 intentional burn injuries reported in the study; often the cases are different in origin and require different content within a prevention strategy. Interburns (www.interburns.org), a main partner in this research, is currently developing a psychosocial training course to help develop capacity in addressing this complex and sensitive issue.

All further burn prevention efforts and health training should use local, relevant data in its development. A good example is the Interburns developed 'Basic Burn Care' (BBC) model; a course which covers first aid and prevention, simple dressings and complications. ${ }^{14} \mathrm{BBC}$ has already been conducted in Nepal, where the burn training for health workers was co-created with the community. The content of the course has been driven by local needs and informed by local people to ensure that it aligns with the needs of the community. BBC demonstrates a very appropriate model of the community being at the center of both prevention interventions and health worker training.

This study illustrates that the risks of burn injury are perpetuated by a variety of social and environmental factors and therefore prevention programs will need to take a holistic and contextually sensitive approach. Both the survey and the qualitative data collection methods were designed with substantial involvement from local stakeholders, and this level of involvement should carry on for future burn prevention and training actions. The study has provided a rich knowledge base on the current burn situation and highlights the importance of involving the local communities in order to produce meaningful results.

\section{CONCLUSIONS}

All of the burns reported in the survey happened in the household, with far fewer burns occurring in households with a separate 'house' for cooking. The most 'at-risk' groups highlighted by the survey were women and children, with many families relying on traditional treatment options. Local health leaders acknowledged that there is a lack of capacity in the local health services in terms of dealing with patients presenting with burns. The recommendations from this research, therefore, are to implement communitybased burn awareness activities which support the community to learn about measures they can take to prevent burns, as well as appropriate first aid options and appropriate referral practices when faced with a burn injury. This should be supported by the provision of training to improve the capacity of healthcare workers to manage burns when needed. Given the need to include all members of a community in such an initiative, future work should include traditional medicine practitioners and herbalists to allow them to give appropriate care for patients presenting to them with burn injuries.

\section{ACKNOWLEDGMENTS}

Ethical clearance was obtained from the Ethiopian Public Health Institute Ethical Review Committee of the Federal Democratic Republic of Ethiopia.

\section{FUNDING}

This research was funded by the National Institute for Health Research (NIHR) (16.137.110) using UK aid from the UK Government to support global health research. The views expressed in this publication are those of the author(s) and not necessarily those of the NIHR or the UK government.

\section{AUTHORSHIP CONTRIBUTIONS}

BD - In country investigator, data collection and supervision, reviewed the draft of the paper providing revisions. $\mathrm{CH}$ - Drafted the paper. AM - Data collection and supervision, reviewed the draft of the paper providing revisions. MA - Data collection and supervision, reviewed the draft of the paper providing revisions. KN - Reviewed the draft of the paper providing revisions providing revisions. MD - Reviewed the draft of the paper providing revisions providing revisions. PP - Conceived the ideas and the experimental design of the study, reviewed the draft of the opaper providing revisions. TP - Principal Investigator, conceived the ideas and the experimental design of the study, reviewed the draft of the paper providing revisions. All authors have seen and agreed the final version of the paper.

\section{COMPETING INTERESTS}

The authors completed the Unified Competing Interest form at www.icmje.org/coi_disclosure.pdf (available upon request from the corresponding author), and declare no conflicts of interest. 


\section{CORRESPONDENCE TO:}

Baye Denekew

Amref Health Africa in Ethiopia, Addis Ababa, Ethiopia.

Baye.Denekew@Amref.org
Submitted: February 16, 2021 GMT, Accepted: April 20, 2021

GMT 


\section{REFERENCES}

1. Marmot M, Friel S, Bell R, Houweling TA, Taylor S. Closing the gap in a generation: health equity through action on the social determinants of health. Lancet. 2008;372(9650):1661-1669. doi:10.1016/S014 0-6736(08)61690-6

2. World Health Organisation. A WHO Plan for Burn Prevention and Care.; 2008. https://apps.who.int/iris/b itstream/handle/10665/97852/9789241596299 eng.pd f;jsessionid=CCFF5A068AF34F416320747C05C62A6 4? sequence $=1$

3. Peck MD. Epidemiology of burns throughoutthe world.PartI: Distribution and riskfactors. Burns. 2011;37:1087-1100.

4. World Health Organisation. Burns. Published 2020. Accessed February 12, 2020. https://www.who.int/ne ws-room/fact-sheets/detail/burns

5. Kearney L, Francis EC, Clover AJ. New technologies in global burn care - a review of recent advances. International Journal of Burns and Trauma. 2018;8(4):77-87. http://www.ncbi.nlm.nih.gov/pubme $\mathrm{d} / 30245912$

6. OECD. DAC List of ODA Recipients. Effective for reporting on 2020 flows. Published 2020. Accessed July 16, 2020. https://www.oecd.org/dac/financing-su stainable-development/development-finance-standar ds/DAC-List-of-ODA-Recipients-for-reporting-2020-fl ows.pdf

7. Central Statistical Agency. Ethiopia Demographic and Health Survey.; 2016. Accessed July 30, 2020. http s://dhsprogram.com/pubs/pdf/FR328/FR328.pdf
8. Sethi D, Habibula S, Mcgee K, et al. Guidelines for Conducting Community Surveys on Injuries and Violence.; 2004. Accessed March 19, 2021. www.inis.ie

9. Ogada EA, Gebreab AH, Potokar TS. Review of the epidemiology of burn injuries in Ethiopia; implications for study design and prevention. Burn Open. 2019;3(3):75-82. doi:10.1016/j.burnso.2019.0 $\underline{5.002}$

10. Othman N, Kendrick D. Epidemiology of burn injuries in the East Mediterranean Region: A systematic review. BMC Public Health. 2010;10(1):1-10. doi:10.1186/1471-2458-10-83

11. Golshan A, Patel C, Hyder AA. A systematic review of the epidemiology of unintentional burn injuries in South Asia. Journal of Public Health (United Kingdom). 2013;35(3):384-396. doi:10.1093/pubmed/f $\underline{\text { ds102 }}$

12. Rybarczyk MM, Schafer JM, Elm CM, et al. Revue systématique des cas de blessures par brûlure dans les pays à revenu faible et intermédiaire: épidémiologie dans la région africaine de l'OMS. African Journal of Emergency Medicine. 2017;7:30-37. doi:10.1016/j.afje m.2017.01.006

13. Organisation WH. 2014-2023 WHO Traditional Medicine Strategy.; 2013. Accessed October 8, 2020. w ww.who.int

14. Potokar T, Bendell R, Chamania S, Falder S, Nnabuko R, Price PE. A comprehensive, integrated approach to quality improvement and capacity building in burn care and prevention in low and middle-income countries: An overview. Burns. 2020;46(8):1756-1767. doi:10.1016/j.burns.2020.05.02 9 